\title{
Implications of Full Day Kindergarten Program Policy on Early Childhood Pedagogy and Practice
}

\author{
Romona Gananathan \\ University of Toronto \\ Canada
}

\begin{abstract}
The government of Ontario is instituting a comprehensive early learning system that moves childcare and the caring profession into the realm of education through the integration of early education and care. This paper highlights the need for the preservation of care and nurturing, the hallmarks of the "caring profession" within the integrated staff team in Full Day Early Learning in Ontario to ensure quality early child development outcomes and the prevention of the "schoolification" of early learning and care programs. Caring and nurturing are important elements of early childhood education practice and form the basis of effective early child development programs. The value of care in early learning, and recognition for the capacities that ECEs bring to integrated staff teams in early education must be reflected in education policy at a team, school, organizational and systems level to ensure successful staff integration and a caring learning environment that contributes to positive child outcomes.
\end{abstract}

Key words: early learning policy, integrated staff team, schoolification of care

\section{Introduction}

The government of Ontario is instituting a comprehensive early learning system over the next four years (2010-2014). The implementation of Full Day Early Learning (FDEL) in Ontario represents a philosophical shift that is sweeping across Canada, and indeed internationally over the past decade; one that moves childcare and the caring profession into the realm of education through the integration of early

Correspondence concerning this article should be addressed to Romona Gananathan, Ph.D Candidate, Ontario Institute for Studies in Education University of Toronto, 252 Bloor Street West, \#9-238. Toronto, ON M5S 1V6. Electronic mail may be sent to romona. gananathan@utoronto.ca learning and care within the education system (OECD, 2006).

The first phase of the program that is being implemented in 2010/2011 includes an integrated Full Day Early Learning Kindergarten (FDELK) program for 35,000 four and five year old children. The new curriculum framework reflects an inquiry-based approach that is centred on evidence that highlights the importance of social and emotional development on children's learning. The program includes an integrated teaching team comprised of a kindergarten teacher and a designated early childhood educator (ECE) working together within the classroom to provide a play-based early learning environment that brings together the expertise of both professional early educators to optimize early child development.

The newly established College of EarlyChildhood Educators (CECE) recently released its standards of 
practice for registered early childhood educators (RECE) in February 2011. Not surprisingly, the new code of ethics and standards of practice are modeled after the Ontario College of Teachers' code of ethics and standards of practice. However, it is not clear how these standards reflect the pedagogical shifts in current evidence based practice in early child development in a play-based non-didactic learning environment which is central to the new full day kindergarten program philosophy.

Drawing initial observations from early childhood educators who work in the FDELK program, this paper undertakes a critical analysis of the standards of practice of both early education professions in Ontario as well as emerging practices, with a view to deconstructing how policy implicates practice and child development outcomes. Grounded in evidence on attachment that informs "developmentally appropriate" early childhood practice, this paper will (a) discuss how the new standards of practice for ECEs and the newly revised standards of practice of teachers address and reflect current early learning research and pedagogy; (b) provide early observations from the field based on initial data collection on shared early learning practice and pedagogy; and (c) offer recommendations on how the new role of the new professional ECE can effectively shape early learning policy and practice in Ontario.

Recent trends in research and evidence on the science of early child development have shifted the focus to include the critical role that early childhood educators play in shaping learning (Barnett, 2008; McCain, Mustard and Shanker, 2007; Shonkoff \& Phillips, 2000). While these bodies of critical research have shifted the emphasis in early childhood from care to early learning, with a focus on the development of the child rather than the simple transfer of care from parents to care providers, they have also helped us understand and rethink why early nurturing and care is so closely linked to learning and the broader goal of school success.

Caring and nurturing are important elements of early childhood education practice and form the basis of effective early child development programs. The value of care in early learning, and recognition for the capacities that ECEs bring to integrated staff teams in early education must be reflected in education policy at a team, school, organizational and systems level to ensure successful staff integration and a caring learning environment that contributes to positive child outcomes. This paper highlights the need for the preservation of care and nurturing, the hallmarks of the "caring profession" within the integrated staff team in Full Day Early Learning in Ontario in order to ensure quality early child development outcomes and the prevention of the "schoolification" of early learning and care programs.

\section{The Defining Qualities of an Early Educator: Standards of Practice and Care}

The integration of childcare and early education services has been driving staffing change in early learning environments over the past decade (Canada Senate Report, 2009; OECD, 2006). The new architecture of Ontario's integrated early learning program as envisioned by the Premier's special advisor offers a "single program with a single pedagogical and curriculum approach planned and delivered by qualified educators using common space and resources" (Pascal, 2009, p. 18).

Driven by the premise that quality programs are delivered by a diverse, knowledgeable and skilled workforce (Ackerman \& Barnett, 2006; Bellm, 2008; Bernhard, 2003; Early, et al., 2007; Moss \& Bennett, 2006), Pascal (2009) lays out the policy receommendations for FDEL programs for four and five year olds, comprised of an integrated staff team of a certified teacher and a registered ECE. He argues, "Fundamental to the full day learning program are educators with child development knowledge and skills, and an effective parent engagement strategy" (2009, p. 32). Pascal's blueprint for staffing includes 
the creation of a unique professional classification within school boards for ECEs, new requirements for teachers to complete an early childhood Additional Qualification $(\mathrm{AQ})$ course within the next five years on early development, and preparation and planning time for the educator teams. Further recommendations on workforce development include training recommendations such as refocusing the ECE diploma and degree programs to establish an early childhood specialty for 0-8 year olds that would reflect a greater understanding of early development practices. In addition, amalgamation of the College of Teachers and the newly formed College of Early Childhood Educators (Pascal, 2009), to create a more streamlined early learning professional designation.

The Ontario Education Act amendments in 2010 allow schools and school boards to operate the fullday early learning program for four and five year olds, signaling an important shift in the legislative history of care and education in Canada. The new Education Act amendment spells out the shared responsibilities of the teacher and ECE and a duty to cooperate and coordinate in the planning and delivery of the Full Day Kindergarten program; the assessment and observation of children; communicating with families; and maintaining a healthy social, emotional and learning environment. However, "nothing in the duty to cooperate limits the duties of teachers under the Education Act, including duties related to report cards, instruction, training and evaluation of the progress of pupils in junior kindergarten and kindergarten classes, and the preparation of teaching plans" (Grieve, 2010, p. 5). The amendment to the Education Act also requires the teachers and ECEs to be members of their respective colleges, including the newly formed College of Early Childhood Educators, established by statute in 2007 (ECE Act, 2007).

Underlying these recommendations for a unified pedagogical approach in the new Full Day Early Learning Kindergarten Program is the former Kindergarten curriculum as well as a new framework for early learning environments called Early Learning for Every Child Today (ELECT, 2007). ELECT proposes a range of principles including knowledgeable, responsive and reflective early childhood practitioners that reinforce the evidence on attachment in the early years. ELECT (2007, p. 19) states,

Reflective practitioners use an emotionally warm and positive approach which lead to constructive behaviour in children...reflective thinking and empathy have their roots in early relationships, where emotions are shared, communicated and expressed. Empathy is broadened when children share experiences, relate and respect each other in the context of caring, secure relationships with adults.

The ELECT framework includes guidelines for professional practice that encourage educators to "create supportive, trustworthy and pleasurable relationships that enable children to benefit from early learning opportunities" (ELECT, 2007, p. 77). For example, it states, "It is by being treated with fairness and empathy that children develop empathy" (ELECT, 2007, p. 44).

However, the new Kindergarten curriculum chooses to focus on the environment rather than delving into the quality of the relationships themselves. For example, the document states,

A supportive social environment has a positive
impact on children's learning. Children are more able
and more motivated to do well and achieve their full
potential in schools that have a positive school climate
and in which they feel safe and supported. 'School
climate' may be defined as the sum total of all the
personal relationships within a school (Ministry of
Education, 2010, p.4).

Similarly, the curriculum suggests that staff teams should ensure the learning environment is inclusive, where children feel comfortable and safe because the atmosphere is vital to the emotional development of children (Ministry of Education, 2010, p. 35). However, 
staff responsiveness is generally aimed at how the practitioners respond to a child's learning and inquiry rather than their social and emotional needs (Ministry of Education, 2010, p. 25-26). For example, the curriculum includes examples of narrative modes of assessment such as "saying, doing and representing" that capture children's learning within the contexts of relationships and environments, which interplay with the team's intentional interactions such as "responding, challenging and extending" and are focused on the child's learning needs. The differences in the philosophical underpinnings of these curriculum documents reflect an underlying dichotomy between care and education.

In 2007, the provincial government announced the establishment of a regulatory College of Early Childhood Educators (CECE) that would undertake the role of maintaining professional standards of practice amongst early childhood educators (Ontario MCYS, July 2007). Registration in the College requires a minimum qualification of a two-year post-secondary Early Childhood Education diploma or equivalent. The first college of its kind in Canada, the CECE mandate includes setting professional standards of practice and a code of ethics, establishing requirements for professional qualifications, developing a public complaints process and providing supports for ECEs to upgrade their qualifications (CECE, 2010).

The CECE has recently released its new standards of practice that governs the practice of Early Childhood Educators in Ontario, outlining six standards that all registered ECEs must adhere to as well as a code of ethics to guide the profession. Interestingly, the first standard of practice is entitled "Caring and Nurturing Relationships that Support Learning" and focuses on the relationship with the child and their families. It states (CECE, 2011, p. 13):

Early Childhood Educators establish professional and caring relationships with children and families. They engage both children and their families by being sensitive and respectful of diversity, equity and inclusion. Early Childhood Educators are receptive listeners and offer encouragement and support by responding appropriately to the concerns and needs of children and families.

The Code of Ethics includes responsibilities to children, families, colleagues and the profession, as well as to the community and society. Again, the focus on caring and nurturing relationships with children is paramount. Section A of the Code of Ethics (CECE, 2011, p. 11) states:

Early Childhood Educators make the well-being and learning of all children who are under their professional supervision their foremost responsibility. They value the rights of the child, respecting the uniqueness, dignity and potential of each child, and strive to create learning environments in which children experience a sense of belonging. Early Childhood Educators are caring, empathetic, fair, and act with integrity. Early Childhood Educators foster the joy of learning through play-based pedagogy.

Similarly, the newly revised Ethical Standards of the College of Teachers (2010, p. 9) include standards of care, respect, trust and integrity, albeit with a focus on academic learning. For example, the standards of "care" and "trust" are described as follows:

The ethical standard of Care includes compassion, acceptance, interest and insight for developing students' potential. Members express their commitment to students' well being and learning through positive influence, professional judgment and empathy in practice. Trust embodies fairness, openness and honesty. Members' professional relationships with students, colleagues, parents, guardians and the public are based on trust.

Similarly the Standards of Practice for the teaching profession include a "commitment to students and student learning" (OCT, 2010, p.13) which states:

Members are dedicated in their care and commitment to students. They treat students equitably and with respect and are sensitive to factors that influence 
individual student learning. Members facilitate the development of students as contributing citizens of Canadian society.

While the Standards of Professional Practice of both colleges clearly reflect the nurturing of children's social and emotional development, there is some divergence in the day-to-day pedagogy and practice of both professionals. This may be attributed to a culture of litigation and complaints against teachers that has resulted in "no touch policies" in school environments.

An initial exploration into the no touch policies of school boards reveal that these policies are largely in place to deter educators from using excessive force in disciplining their students. For example, in the Elementary Teachers' Federation of Ontario's (ETFO) resource document entitled, "Use of Restraint Advice" aimed at its members, the union cautions that:

Using force to discipline a student puts teachers at a particularly high risk of being accused of assault. The Criminal Code provides only a limited defence to teachers correcting students by force....many boards have a 'hands off', 'no touch' policy in relation to discipline. For this reason it is critical that all members take precautionary steps to avoid physical contact with students except where it is needed and in accordance with board policy (ETFO, 2011).

Similarly, the Ontario English Catholic Teachers' Association (OECTA), Spring 2010 newsletter outlines:

To date this year we have had four complaints reported to the CCAS. Two complaints were dismissed as unfounded. Nonetheless, the teachers involved were placed under a great deal of stress. The other two have not yet, been resolved. It is important to follow the 'Be Wary, Be Wise' directive during your daily teaching activities. Be professional at all times and avoid 'touching' students.

Unfortunately, these directives inform and affect the day-to-day interactions between educators and students, permeating these caring and nurturing relationships with a sense of caution and surveillance that does not exist in the childcare environment. Despite a nurturing approach in professional standards for teachers, Piper and Stronach (2008), found that early years practitioners are aware of the prevailing no-touch norm and, for the most part, act accordingly, even when (in some instances), they may be aware that this response is to the detriment of the young child. The study also found that educators were aware that a demonstration of the caring nature of the practitioner or "caregiver" would have been more appropriate in that particular situation. The authors discuss the irony of these professionals who are seemingly more concerned about others watching them than their own appropriate response to meet the immediate needs of the child (e.g., a hug to make the hurt go away).

Similarly, Lawson (2008, p.95) also found that educators had their own views on touch and while they felt that not touching children could be detrimental to their emotional and physical well being, there was no agreement on the parameters of touching. Some teachers had no qualms about using reassuring touch, whereas other felt that touching a child that was merely seeking comfort and reassurance was a minefield. Unfortunately, these policies and resulting practices do not reflect what we know about the benefits of care, nurturance and attachment, particularly in early learning environments. Ironically, these policies exist in situations where schools promote "a caring and family ethos" (Lawson, 2008, p. 95).

\section{Reflections on Integrated Practice in the ELP}

The foundational aspects of the integrated FDEL program in Ontario include a caring, nurturing and play based curriculum framework, which the new professional ECE brings to the education sector. It heralds the re-engineering of the Early Childhood 
Educator (ECE) within the education sector as an equal partner with the kindergarten teacher, and a professional with early education expertise in the early learning classroom: one can offer meaningful expertise in early learning curriculum pedagogy and practice rather than the historical construction of the ECE within school settings as a classroom assistant and care provider which furthered the false dichotomy between learning and care.

According to a recent response paper from the Atkinson Centre (2010), there are some very good examples of teaching partnerships between ECEs and teachers in the full day kindergarten program. However, what is also abundantly clear are ongoing structural challenges to establishing stronger partnerships with uneven planning time for the educator team and full day kindergarten classrooms, many operating with larger numbers of children than the recommended 26 per class. In a study of the Peel District School Board, nearly a third of the teachers reported overseeing more than 26 children (Hammer, 2010). Initial results also point to differentials in pedagogy, where early childhood educators are being discouraged from being affectionate and caring in their classroom practice.

As part of my doctoral research on the changing role of the Early Childhood Educators in the Early Learning Programs, I have interviewed several Early Childhood Educators in 2011, on their early experiences in the programs. There have been accounts of positive relationships with team teachers and administrators in the schools; parents and families who are beginning to understand the changing role of the ECE as early educators in the classroom; and ECEs who are able to utilize their skills and expertise in child development to plan and implement programming in partnership with their teachers. However, ECEs also described their frustrations with their inability to transfer their knowledge and skills on child development from the childcare sector into the education context. Many are struggling with the cultural shift from early childhood environments where children thrived with caring and nurturing relationships with their educators, to the school environments where there is a culture of suspicion and mistrust of educators.

Initial results (Gananathan, 2011) on the role of the Early Childhood Educators who are working in the Early Learning Program in Ontario and their shared practice and pedagogy with teachers raises questions with respect to the issue of care and nurturing. For example, one ECE stated that the school has a "no touch policy" that does not permit the ECE to hold a child's hand while walking down the hallway; she has been cautioned by her teacher colleagues not to hold hands with students. She described that in childcare, the practice of holding a 4-year old child's hand while walking down a hallway would be completely acceptable given the social and emotional connection between the child and their caregiver. However, in a school setting, she struggles not to take the hand that the child reaches up, to avoid brushing up against the school's no hands policy. She said:

It's really hard, when you are walking down the hallway and a child reaches up to take your hand, as an ECE, you don't even have to think about it...you just take their hand. After all, they are just 4 , some are not even 4 yet, and it is completely natural for them to reach up to hold your hand. Now I have to think about it and I even got told by other teachers in the school not to do it. Not my teaching partner, but another teacher that saw me holding a student's hand (ECE-A, 2011).

In another example, an ECE (ECE-B, 2011) described a situation that arose when a child was sick after eating lunch. She was alone in the classroom with the children because the teacher was on her lunch break. When she called the office she was asked to send the child to the office and call his home to have him picked up, because she was not allowed to help him clean himself up. The child was forced to sit in his dirty clothes for almost an hour while he waited to be picked up, because of the school's no touch 
policy. The ECE questioned how this would impact the child's social and emotional well being with respect to his embarrassment with his peers and his self-esteem. She voiced her concerns to me about not being able to reconcile her desire to "do the right thing" and follow her ECE training to respond to the child in that particular situation, and her discomfort with being unable to reconcile this with the schools no touch policy. These examples highlight the need for reconsideration of daily routines and practices in schools, which may cause emotional distress for the child. Educators need to revisit their professional standards of practice that emphasize caring and empathy as foundational principles, to shift to a more humane approach of dealing with such incidents.

In another example (ECE-C, 2011), an ECE described how a young four year old child in her JK class was having a difficult time self-regulating while coming in from the playground. The child was sitting on the ground in the locker area crying loudly and refusing to take his coat off and enter the class because of an incident with another child in the playground. In a childcare setting, the ECE stated that she would have picked the child up, sat him down on her lap and helped him to calm down and refocus, which reinforces the important links between responsiveness and self-regulation in children. However, she described her frustration with not to be able to help the child because she was constrained by the no touch policy in the school. Since she was unable to intervene as trained in a more caring and nurturing manner the situation became much worse and the child's behaviour lasted much longer. She felt that there needed to be a greater focus on the child's social and emotional needs and a better understanding of the role that early educators can play to support this development in the school environment. Despite what the standards of practice outline in terms of establishing caring and nurturing relationships and the need to be responsive professional educators, in this case, the ECE is following the expectations of the school with respect to her behaviour.
All of the ECEs that I interviewed expressed their concerns about the lack of understanding of their role in the school system, and their frustrations about being constrained by school policies that prevent them from responding to their young students needs in caring and nurturing ways that are central to their early child development training. Many stated that they continued to practice what they believed was the appropriate response, whenever they were able to do so. For example, one ECE described how she assisted a child who had a toileting accident, regardless of the schools policy although she made sure that her teacher partner was present in the room while she did so. Clearly, the cooperation of her teaching partner was important to allow both educators to respond appropriately. She also reported the incident to the parent, who was very grateful for the caring intervention, which allowed her child to spend the rest of the day in school. However, ECE felt frustrated by the lack of understanding of her role in the school. She stated,

In the beginning of the year we had a very young child, who didn't turn four until November and it was a big transition for him with the accidents and toileting... and the teacher said that she is not allowed to assist in the washroom and he was left on his own...until she realized that I was an Early Childhood Educator and she said, 'wait, you can help him'. I know that is the role of the Educational Assistants in the school, but I just helped him because he needed assistance at that time.

These examples reflect the culture of the school system, which focus on academic outcomes and are somewhat ambivalent about the notion of play-based learning and the need for caring and nurturing relationships to support learning. The schools' no touch policies in large part stem from the need to protect educators from allegations of improper conduct that can result in disciplinary measures through the College of Teachers. In fact, the Elementary Teachers' Federation of Ontario, the 
largest union that represents over 76,000 elementary school teachers in the public system in Ontario has a posted precautionary measures for its members to follow that encourages teachers to, "wherever possible avoid physical contact with students" (ETFO, 2011). However, the number of complaints and allegations are few considering the number of teachers in Ontario. For example, the 2009 annual report lists 117 complaints against teachers for "abuse of a student" and 96 complaints of "conduct unbecoming a teacher", with only 11 members suspended from teaching as a result (OCT, 2011). The allegations of abuse represent only .04\% of the total 224,000 members of the College. The College of ECE has had only nine complaints filed against its 30,000 members with none referred to the discipline committee (CECE, 2010) as yet.

At the same time, there is a sense that not only ECEs, but many teachers also disagree with the no touch policies. It is encouraging that there is a trend towards the nurturing of caring relationships in the school system both in Ontario and in the broader context. For example, Michael Gove, the Education Secretary in the United Kingdom, states, "If we stigmatise and seek to restrict all physical contact between responsible adults and children we will only undermine healthy relations between the generations, and make children more suspicious about adults and adults more nervous and confused about their role in our society" (Garner, 2011). Research also suggests that "social and behavioral skills have a positive effect on the growth of academic skills in the early elementary grades" and that "the teachers who are good at enhancing social and behavioral skills provide an additional indirect boost to academic skills in addition to their direct teaching of academic skills" (Jennings \& DiPrete, 2008, p.1).

\section{Conclusion: The Defining Qualities of Integrated Early Learning and Care}

The OECD (2006) suggests that there is a societal shift away from traditional notions of childcare to include more development ambitions for children in early learning that leads to improved outcomes for children. As a result, there is an emergence of a new professional ECEC profile that is trained to work with both young children and families in countries such as Sweden, New Zealand and Norway (Bennett, 2008). Ontario's new ECE role similarly sets up the new education professional to function within an integrated team comprised of a teacher and ECE in the education system. However it is not clear how these roles will be shaped over time and whether the defining qualities of care and nurturing that are the hallmarks of the Early Childhood Educator will permeate Ontario's Early Learning Programs.

It is critical to acknowledge both teaching roles in the integrated model, although the learning is acquired differently and may be executed differently. For example, some of the key questions raised in the OECD countries include whether there is a core professional in integrated staff teams, what the balance between professional and "assistant" would be; what level and type of education these professionals will have; and who will pay for their training and improvements to the workforce $(\mathrm{OECD}$, 2004).

Full service integration requires an infusion of interprofessional practices and expertise combined with action at numerous levels including government policy, governance, leadership, organizational culture and ethos, and frontline professional practice and teamwork (Press, Sumsion \& Wong, 2010). Interprofessional practice requires the ability to articulate one's own disciplinary specific knowledge base and skills, while being able to look beyond its boundaries to appreciate different practices and negotiate differences in priorities. Boards, administrators and principals that have not previously had early childhood educators as members of their staff need to take leadership to broaden the scope of professional practice in early learning environments. They need to ensure that the stage is set to welcome these new early 
educators at the school level, and acknowledge the expertise in child development that they bring to the classroom. In schools where early childhood educators have already been part of the staffing team, discussions about how the role is changing with this new vision of early learning will be important (Speir, 2010). Fundamental to this revision will be the caring and nurturing role that both teachers and early childhood educators can play in the early learning program.

Given the history behind no touch policies and the renewed investments in early child development in Ontario, it is time to revisit and rethink the implicit and widespread no touch policies and their implications for children's development and learning experiences. There is an opportunity to reframe early learning programs, and put the needs of the children at the core of early learning pedagogy and practice, that integrates both the perspective of the child as well as the adult professional. We need to re-connect with standards of practice that demonstrate the caring nature of both early learning educators as caregivers, and reconsider the conditions under which and by whom touching is appropriate and preferred, in order to reduce prejudices in the classroom and eradicate societal stereotypes of touch and touching (Piper \& Stronach, 2008).

These issues challenge trainee early childhood practitioners to develop a strong understanding of the link between quality early learning environments, and the critical importance of integrating social emotional support to ensure success in learning. It is, therefore, imperative to reflect on the systemic issues that get in the way of caring and nurturing in early learning practice within an early learning framework that is focused on literacy and numeracy outcomes.

The Toronto First Duty program, a model of early education service integration where preschool, parenting and kindergarten programs operate under one umbrella has gained much attention locally, nationally and internationally (Corter et. al., 2009). The report concludes:
Fundamentally, the research evidence points to the integration model as a positive and effective learning environment for young children. It highlights the capacity of professionals from education and early childhood to work collaboratively and to build on the strengths of each. It recognizes the absolute importance of reciprocal mentoring and a professional respect for each other. Teaching became seamless across the two professions (p.13).

However, a key finding of the Toronto First Duty evaluation is a need for systems wide structural change to ensure effective integration, rather than an expectation of best practice pedagogy amongst educators.

The ongoing challenge for the newly created professional ECE in school settings will be to gain the professional recognition that is afforded to teachers in the early learning classroom. Supports to successful integration and professional recognition include joint professional learning opportunities that can support reciprocal learning, and have been proven to change staff perceptions about the benefits of working in an integrated team (Janmohamed and Pelletier, 2010). A foundational concept in the Reggio Emilia approach is the need for collaboration amongst staff. According to Speir, (2010, p. 24), the Emilia approach espouses a belief system that:

A group has a greater intelligence than an individual. This theme of collaboration and reciprocity is mirrored in the structure of classrooms containing two teachers who work together with the same group of 26 children. The sharing of different perspectives brings new ideas and interesting approaches, evidenced by the documentation and interpretation that these differently trained educators produce and render through discussion.

The Toronto First Duty demonstration site has demonstrated that such coordination of preparation time is "not only sensible, but also deepens professional collaboration through joint curriculum 
planning (Janmohamed \& Pelletier, 2010, p.20).

There are many structural and political barriers in administration as well as professional and historic barriers in pedagogic practice to overcome an integrated approach to ECEC services for kindergarten-aged children in Canada. "The goal is to strive for collaboration, mutual respect between sectors and communities and develop options based on collective imagination" (Colley, 2005, p. 31). Despite the enthusiasm for integrated early education and care, Press, Sumsion and Wong (2010) warn against a "one-size fits all" approach to integration. They suggest that policy and professional development programs should recognize the value of diverse approaches rather than advocating for a standardized model.

But where does that leave Ontario's new early education professional? On the one hand, the everyday pedagogical practice of the early learning classroom can shape the long-term professional role, identity and recognition of the new Early Childhood professionals. However, Speir (2010, p. 24) rightly argues, "Structures will need to be in place to support the two educators and help them develop a collaborative learning process, ensuring that each voice and opinion is heard and respected. There is much more to the successful implementation of this process than simply putting two educators in one room." This reinforces the findings of the Toronto First Duty program that effective governance is critical to ensure staff integration is successful.

Corter et al. (2009, p. 10) state, "The staff team pathways are the critical, and interwoven design strands we need to focus on at the very beginning of implementation". Fullan (2001, p. 130) captures the significance of the day-to-day practice of organization change when he states:

Organizations transform when they can establish mechanisms for learning in the dailiness of organizational life. People make...fundamental transitions by having many opportunities to be exposed to ideas, to argue them to their own normative belief system, to practice the behaviours that go with those values, to observe others practicing those behaviours and most importantly to be successful at practicing in the presence of others (that is, to be seen to be successful).

The labour movement must consider child care a priority. Advocating, organizing and bargaining are inter-connected strategies that would make good use of the movement's structure and experience (Doherty, 2002). For example, unions could play a greater role in helping early educators understand the situations in which caring, nurturing and safe touch practices can contribute to early development, rather than focusing on the fears of how touch and caring interactions will be construed by others.

In addition, a staged approach to skills upgrading has been a key to ensuring that staff that are hired into integrated early learning environments can move towards a common ground in training and skill levels. For example, in New Jersey, the court ordered that early learning staff upgrade to a four-year child development focused degree over time, which resulted in $95 \%$ of the staff meeting these expectation (Press, Sumsion \& Wong, 2010). Similarly, Prince Edward Island's integration efforts include increased requirements for early childhood educators to complete 20 additional courses at a university level and for kindergarten teachers to complete a Bachelor of Education degree and take courses specific to early childhood education (Mella, 2009). The recomme-

ndation that all kindergarten teachers in the early learning program complete an additional qualification course in early development will be helpful towards creating a greater understanding of early child development theories such as attachment and care. Finally, training must be provided to school boards and administrators on a more consistent and accessible basis to ensure systemic change and coordinated outcomes across the province in relation to staff integration and the professional recognition of the new ECE role. 
Ontario's current policy direction focuses on implementing a Full Day Kindergarten Program with an increased emphasis on schooling. However, adequate attention is not being paid to educator qualifications and program quality that could contribute to child development outcomes. Despite the policy intent of shared responsibility to plan and implement curriculum together, the limit placed on the duty to cooperate confirms the "lead" role of the teacher in the classroom with respect to instruction, assessment and classroom management (Grieve, 2010, p.5), leaving the ECE in a precarious position in the classroom, having to negotiate their responsibilities and roles with their teaching partner in an attempt to co-operate. Given the complexities of the institutionalized education setting and the relative lack of power of the new professional ECE in the early learning classroom, great care must be taken to ensure that we do not lose the policy and program intent articulated in the special advisors report with respect to care and nurturing in integration. It can only be achieved with an ongoing and multipronged approach of strategic legislation and policy; union collaboration and political support; training and infrastructure support for school boards and administrators; and professional development for the teaching teams.

\section{References}

Ackerman, D., \& Barnett, W. S. (2006). Increasing the effectiveness of preschool programs (Preschool Policy Brief Issue 11). NJ: NIEER.

Atkinson Centre for Society and Child Development. (2010). Ontario lacks vision and leadership in early learning. Retrieved from http://www.oise.utoronto/ atkinson/UserFiles/File/AC_E DP_ Amendment_ change_analysis.pdf

Barnett, W. S. (2008). Why governments should invest in early education. CESifo-DICE report, 6(2), 9-14.

Bellm, D. (2005). Establishing teacher competencies in early care and education: A review of current models and options for California. Berkeley, CA: Institute center for the Study of Child Care Employment, University of California at Berkeley.

Bennett, J. (2008). Early childhood services in the OECD countries: Review of the literature and current policy in the early childhood field (Innocenti Working Paper No. 2008-01). Florence, Italy: UNICEF Innocenti Research Centre.

Bernhard, J. (2003). Toward a 21st century develo pmental theory: Principles to account for diversity in children's lives. Race, Gender, and Class, 9(4), 45-60.

Best Start Expert Panel on Early Learning (2007). Early Learning for Every Child Today: A framework for Ontario early childhood settings. Toronto, Ontario: Ministry of Children and Youth Services.

Canada Senate Report. (2009). Early childhood education and care: Next Steps. Retrieved from http://www.parl.gc.ca/Content/SEN/ Committee/402/soci/rep/rep05apr09-e.pdf

College of Early Childhood Educators. (2010). Seizing opportunity: 2009-2010 annual report. Retrieved from http://collegeofece.on.ca/en/Documents/ Annual\%20Report\%200910.pdf

College of Licensed Practical Nurses of Alberta. (2011). Code of ethics and standards of practice. Retrieved from http://www.clpna.com/Portals/0/Files/ doc_CLPNAEthicsStandards.pdf

Colley, S. (2005). Seeing the Future: An Answer to questions of integration. Toronto, Ontario: The Integration Network Project, Institute of Child Study, Ontario Institute for Studies in Education/University of Toronto.

Corter, C., Pelletier, J., Janmohamed, Z., Bertrand, J., Arimura, T., Patel, S., Mir, S., Wilton, A., Brown, D. (2009). Final research report. Toronto, Ontario: Atkinson Centre for Society, Institute of Child Study/Department of Human Development and Applied Psychology, Ontario Institute for Studies in education/University of Toronto.

Doherty, G. \& Forer, B. (2002). Unionization and Quality 
in Early Childhood Programs. Ottawa: Canadian Union of Public.

Early, D. M., Maxwell, K. L. Burchinal, M., Soumya, A., Bender, R. H., Bryant, D., et al. (2007). Teachers' education, classroom quality and young children's academic skills: Results from seven studies of preschool programs. Child Development, 78(2), 558-580.

Early Childhood Educator Act. (2007). Statute of Ontario. Retrieved from http://www.elaws. gov.on.ca/html/statutes/english/elaws_statut es_07e07_e.htm

Elementary Teachers' Federation of Ontario. (2011) Advice for members/PRS bulletins, Toronto. Retrieved October 11, 2011, from http://www. etfo.ca/AdviceForMembers/PRSMattersBulleti ns/Pages/Use \%20of\%20Restraint\%20Advice\% 20to \%20Members.aspx

Fullan, M. (2001). Leading in a culture of change. CA: Jossey-Bass.

Gananathan, R. (2011). Professionalizing early childhood education. Doctoral Study, University of Toronto (In Process).

Grieve, J. (2010). Legislative Changes Under Bill 242, Memorandum to Directors of Education, Retrieved from http://cal2.edu.gov.on.ca/may2010/ 2010EL6_Bill242.pdf

Garner, R. (2011, January 8). Teachers can touch children, says gove. The Independent, Retrieved from http://www.independent.co.uk/news/ education/educationnews/teachers-can-touchchildren-says-gove-2179159.html

Hammer, K. (2010, December 6). Full-day kindergarten popularity outstrips plans to pay for it. Globe and Mail, Retrieved from http://www. theglobeandmail.com/news/national/toronto/ki ndergarten/full-day-kindergarten-popul arityoutstrips-plans-to-pay-for-it/article182674/

Janmohamed, Z. \& Pelletier, J. (2010). Implementing early learning programs in Ontario schools. OPC Register, 12(2), 17-20.

Jennings, J. \& DiPrete, T. (2008). Teacher Effects on
Social/Behavioural Skills in Early Elementary School. New York: Columbia University.

Lawson, H., (2008). Case Study: Primary and Junior Schools. In H. Piper \& I. Stronach (Eds), Don't Touch! The Educational Story of a Panic. New York: Routledge.

McCain, M., Mustard, J., \& Shanker, S. (2007). Early years study 2: Putting Science Into Action. Toronto, Ontario: Council of Early Child Development.

Ministry of Education. (2010). Full Day Early Learning Kindergarten Program. Toronto, Ontario: $\mathrm{Q}$ ueens Printer for Ontario.

Moss, P. \& Bennett, J. (2006, September). Toward a new pedagogical meeting place? Bringing early childhood into the education system. Briefing paper for a Nuffield Educational Seminar. Retrieved from http://childcarecanada.org/sites/childcarecan ada.org/files/Bennett\%20and\%20Moss\%20(20 06)\%20Towards $\% 20 a \% 20$ pedagogical $\% 20$ meeti ng\%20place.pdf

Mustard, F. (2008). The Quality of Public Education in Canada. The Learning Partnership, Issue 4.

OECD. (2004). Early Childhood Education and Care Policy: Canada Country Note. Paris: Directorate for Education, OECD.

OECD. (2006). Starting Strong II: Early Childhood Education and Care. Paris: OECD Publishing.

OECTA. (2010). Occasionally Speaking. Retrieved from http://www.totloecta.org/TOTLSpring2010.pdf

Ontario College of Teachers. (2010). Foundations of Professional Practice. Retrieved from http://www. oct.ca/publications/pdf/foundation_e.pdf

Ontario College of Teachers. (2011). Annual Report 2009, Retrieved from http://www.oct.ca/annual _report/2009/en/home.html

Ontario Ministry of Children and Youth Services. (2007, July 5). McGuinty government strengthens Ontario's child care system, Canada NewsWire. Retrieved from http://www.newswire.ca/en/ story/142187/mcguinty-governmentstrengthens-ontario-s-child-care-system

Pascal, C. (2009). With our best future in mind: 
Implementing early learning in Ontario. Toronto, Ontario: Queens Printer for Ontario.

Pascal, C. (2009). Every child, every opportunity: Curriculum and pedagogy for the early learning program. Toronto, Ontario: Queens Printer.

Piper, H., \& Stronach, I., (2008). Don't touch! The Educational Story of a Panic. New York: Routlege.

Press, F., Sumsion, J., \& Wong, S. (2010). Integrated Early Years Provision in Australia. Bathurst, NSW: Charles Sturt University.

Shonkoff, J., \& Phillips, D. (Eds.). (2000). From neu rons to neighborhoods: The science of early childhood development. Washington, DC: National Academies Press.

Speir, S. (2010). The Pedagogy of Relationships. OPC Register, 12(2), 22-27. 